\title{
Flexible office, flexible working? A post-relocation study on how and why university employees use a combi-office for their activities at hand
}

\section{Antonio Cobaleda-Cordero*, Maral Babapour and MariAnne Karlsson}

\author{
Division Design and Human Factors, \\ Department of Industrial and Materials Science, \\ Chalmers University of Technology, \\ Gothenburg, Sweden \\ Email: cobaleda@chalmers.se \\ Email:maral@chalmers.se \\ Email:mak@chalmers.se \\ *Corresponding author
}

\begin{abstract}
This study reports on a group of university employees, six months after their relocation from cell-offices into a combi-office. Data from interviews, observations and planning documentation was collected to gain an in-depth understanding of how employees use their office landscape and why. Activity theory was taken as framework for the analysis. The findings show that the new office landscape was perceived to be more flexible and capable of supporting employees' activities. The overall occupancy was low and backup spaces, such as quiet rooms, were barely used. Matches and mismatches between the employees, their activities and the office were identified that explain the occupancy rates and why spaces such as quiet rooms were unpopular spaces. This paper contributes with rich detail on the use of a flexible office landscape in a university context and shows the usefulness of activity theory in the study of employee-office interactions.
\end{abstract}

Keywords: office use; office landscape; flexible office; flexible working; combi-office; spatial attributes; activity theory; post-relocation study.

Reference to this paper should be made as follows: Cobaleda-Cordero, A., Babapour, M. and Karlsson, M. (2020) 'Flexible office, flexible working? A post-relocation study on how and why university employees use a combi-office for their activities at hand', Int. J. Human Factors and Ergonomics, Vol. 7, No. 1, pp.26-54.

Biographical notes: Antonio Cobaleda-Cordero is a $\mathrm{PhD}$ student at the Chalmers University of Technology with a background in Industrial Design Engineering. He has a strong interest on product design and development as well as on the user experience that they provide. His research focuses on the relationships between employee well-being and office landscape attributes (e.g., spatial features, layout, functions, artefacts and environmental conditions) in the context of use.

Maral Babapour is a design researcher, at the Chalmers, with a focus on workplace design and occupational health and safety management from a user-centred design perspective. Her $\mathrm{PhD}$ thesis addressed impacts of activity-based flexible offices (AFO) on employees' and their work over time. 
She has studied and evaluated various AFO implementations from an innovation adoption perspective, using a variety of qualitative and quantitative methods. Her contributions include mapping of success factors and sub-optimal features in design, planning process, and management of work environment in AFOs.

MariAnne Karlsson is a Professor in Human-Technology Systems at the Chalmers University of Technology. Her research aims to develop knowledge on the relationship between people and products in different contexts. Her central themes concern methodology for eliciting user requirements functional as well as affective - for new technical products and systems and prerequisites for individuals' adoption of new technical solutions.

\section{Introduction}

Office types have usually been characterised by spatial attributes that mainly denote their architectural and functional features that influence employees' work conditions [cf. cell-office vs. open-plan office in Danielsson and Bodin (2008)], and define the uses that they are supposed to make of the space (De Been and Beijer, 2014; De Croon et al., 2005). Examples of these spatial attributes are zoning, room layout, number of workstations per room, level of workstation seclusion, etc. In the case of more recent office types, such as activity-based flexible offices or combi-offices (Danielsson and Bodin, 2008), their design is oriented to support flexible ways of working and there is no strict definition of their spatial attributes (Danielsson, 2016). This means, for example, that two offices for flexible working can be highly distinct office landscapes (OLs), i.e., particular physical office environments materialised in unique constellations of spatial attributes. To enable flexible working, employees share different spaces at their availability so that they can choose the one that best fits the activity at hand, for example spaces for interaction, collaboration or socialisation; quiet rooms for concentrative work; phone booths for making phone calls; and meeting rooms of different types, sizes and equipment, etc. A key difference between the two latter office types is that combi-offices have a desk assigned to each employee [Van Meel, (2000), p.99], while activity-based flexible offices have shared desks, which reduces the costs of unoccupied assigned desks and floor area (Brunia et al., 2016).

However, OLs designed for flexible ways of working are often not used as intended (Appel-Meulenbroek et al., 2011; Cobaleda-Cordero and Babapour, 2017; Hirst, 2011) and notable differences are observed between case studies regarding satisfaction with work conditions (Brunia et al., 2016) and compliance with desk sharing policies (Babapour and Rolfö, 2018). Recurrent factors underlying the discrepancies between the intended and actual use are inherent to the demands of flexible working, such as looking for and setting up different workstations for diverse activities (Morrison and Macky, 2017), or case-specific circumstances, such as the implementation process (Lahtinen et al., 2015). Nevertheless, these studies mostly address the desk sharing policies and related effects in activity-based flexible offices, while studies focusing on combi-offices are less common. Cross-sectional studies often group office types for flexible working into one category (e.g., Danielsson and Bodin, 2008; Seddigh et al., 2015) or they are addressed in large datasets comparing the impact that different office types have, for 
example on employee satisfaction, from a quantitative point of view (Appel-Meulenbroek et al., 2015; Windlinger, 2013). Although the numbers allow to generalise some conclusions, the explanations on why a certain type of office fits or does not fit the population studied are limited. Hence, there is a value in addressing combi-offices in isolation and more in depth to understand the interrelations between the employees, their activities, the OLs provided and the context, for instance relocations and how organisations deal with them [cf. case studies on activity-based flexible offices in Babapour (2019)].

This paper reports on a group of employees in a Swedish university, six months after they were relocated into a combi-office, in order to investigate the mentioned interrelations more comprehensively. The following research question was formulated as the starting point:

RQ1 How do employees make use of their new combi-office to carry out their activities?

In addition, studies have addressed the impact of a number of context-specific spatial attributes such as the type of furniture, the amount of daylight, acoustics or indoor climate (Haapakangas et al., 2017; Lahtinen et al., 2015; Lamb and Kwok, 2016). These spatial attributes do not determine the type of office but, once again, a specific $O L$. This implies that employees' activities may be influenced by the spatial attributes that are characteristic to the office type, as well as by those related to a specific landscape. Subsequently, if activities are influenced by any spatial attribute, the use that employees make of the OL may be influenced as well.

Therefore, it is here argued that the study of offices needs to move down one level of abstraction, from the office type level to the landscape level. This paper investigates a combi-office at the level of the OL, considering not only the spatial attributes of the office type, but also those related to the landscape to which the group of employees studied was relocated. The aim was to gain a deeper understanding of how and why employees make use of a new OL to carry out their activities, as well as the influence that the spatial attributes therein have on that usage. In this regard, the following research question was formulated:

RQ2 What spatial attributes - if any - influence the use that employees make of the OL and how?

In order to study the use that employees make of an OL and the role that spatial attributes have in that usage, it is necessary to approach the elements involved in the occurrence of using the landscape and their interrelations. The individual and the landscape elements are addressed in person-environment fit theory in the field of organisational psychology (Caplan, 1987; Edwards et al., 2006). However, the use that the employees make of their OLs is not captured through the person-environment fit theory, as this mainly addresses person-related characteristics, such as personality traits (Ostroff and Judge, 2007). A theoretical perspective that focuses on the interrelations between the individual, the $\mathrm{OL}$ and individual's activities in the context of use is activity theory (Engeström, 2000), although it has been rarely applied in office evaluations [a recent exception is Babapour (2019)]. This paper applies an activity-theoretical perspective to gain an in-depth understanding of the mentioned interrelations, in the context of a relocation to a combi-office. 


\section{Framework}

From an activity theory perspective, an individual carries out a purposeful activity mediated by an instrument, which could be any artefact used in the individual's activity (Kaptelinin and Nardi, 2007). In the office context, the employee is the individual who carries out different activities throughout the day, mediated by the spatial attributes of the landscape - referred as instruments in activity theory - and contextual elements such as the social environment, the organisation's policies, employment conditions, work processes, etc.

The activity can be studied at different levels of abstraction: activity, action and operation (Kaptelinin and Nardi, 2007). Activities are linked to the motivations behind a set of actions, for instance the activity of participating in a meeting. In the absence of a motivation there is no activity, although activities, such as office meetings, can have multiple motives. Activities are performed via actions, which are linked to concrete goals defined by the individual, for instance, collecting information relevant for the meeting. At the same time, actions are performed via operations, which are executed without thinking or focusing on them. For example, when browsing folders in the computer to find the information needed for the meeting, the individual will not reflect on how to operate the mouse or trackpad (Bødker and Klokmose, 2011).

The interactions between the elements of the activity as described by Engeström (2000) are dynamic, and alterations in the context or the instrument can lead to different activity outcomes or to breakdowns (Bødker and Klokmose, 2011). Breakdowns occur when there is a mismatch between the activity and what the instrument enables the individual to do, or between the instrument and the individual's repertoire of action possibilities, physical capabilities or preferences.

Subsequently, these two types of mismatches can create a third mismatch between the individual and the activity, by modifying or introducing new necessary actions that were not initially intended by the individual (Babapour, 2019). In the absence of mismatches, instruments align with internalised operations and they practically disappear as artefacts from the conscious level, somehow becoming an extension of the human body (Bødker and Klokmose, 2011), for instance a comfortable sofa that 'vanishes' from the conscious level of an employee that sits on it while reading comfortably. If a breakdown occurs, for example the sofa is occupied, the attention of the individual is drawn to the instrument instead, and the operation of sitting on the sofa becomes a new action - an available sofa must be found. Breakdowns also occur with the introduction of new instruments in the activity that an individual need to learn, which in turn, will lead to the expansion of the individual's repertoire of action possibilities for future activities (Bødker and Klokmose, 2011; Engeström, 2000).

In the office context this necessity for learning becomes evident with office relocations, since employees need to become familiar with the new landscape. Studying employees' activities after relocation, as is the case in this paper, also allows employees to report on matches and mismatches that have recently been experienced that otherwise might have settled in the back of their thoughts.

However, this view on the purposeful interaction of one individual and one mediating instrument is mostly aligned with earlier theoretical models of activity theory. Engeström et al. (1999, pp.29-32) proposed an expanded model of activity systems that represent the societal and collaborative nature of activities. This representation provides a broader 
perspective and meaning to activities that also contribute to identify the underlying rationale behind the breakdowns experienced by individuals. In the office context, activities rarely occur between one individual and a single instrument, rather various individuals [cf. the element 'community' in activity systems by Engeström (2000)] and multiple instruments (Forlizzi, 2008) are involved in activities, for instance a meeting. From this perspective, it is emphasised the need of analysing activities on a social or an individual level depending on the case. In addition, activities may be linked to a narrower focus such as a specific characteristic of an individual (Karlsson, 1996), for example the sociability of an employee in relation to the seclusion of spaces. Thus, the subject of the activity can be represented in the activity system at the level of collectives, individuals or (individuals') characteristics.

Figure 1 Adaptation of the activity theory framework for the study of OL use (see online version for colours)

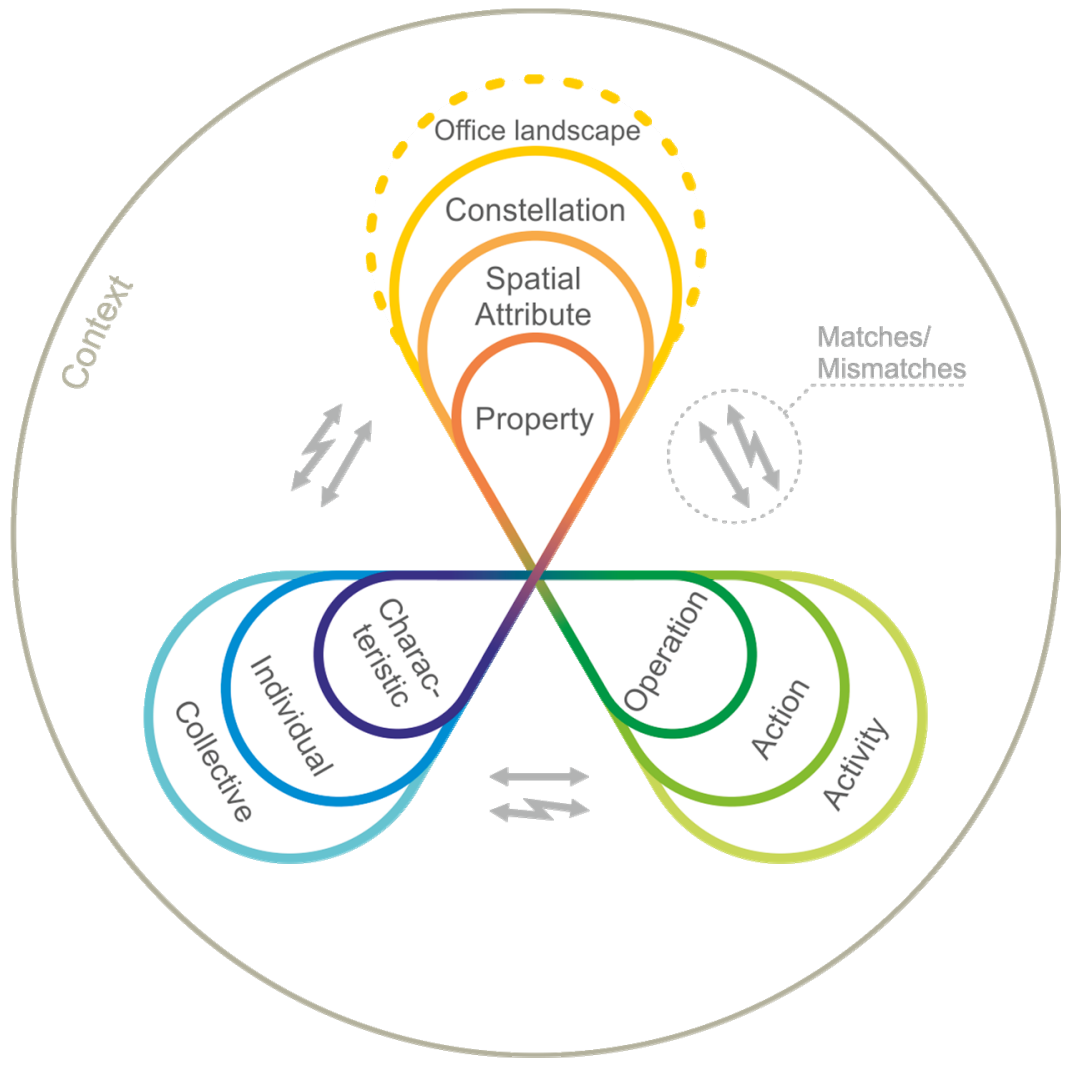

In the case of the instrument it is possible to concretise similar levels of analysis, for example, an entire room could be considered a constellation of spatial attributes that work as a single instrument mediating an activity (Karlsson, 1996). In this paper, the OL can be interpreted as the biggest possible constellation of the activity system studied. Furthermore, the instrument could be a single spatial attribute, such as a desk in a room, or even a design property of this spatial attribute, such as the range of heights to which the desk can be adjusted. 
Other elements of the activity that are referred to in activity theory as rules or division of labour (Engeström, 2000) are here considered part of the context of use of the landscape, since the main focus of this paper is on the spatial domain and the physical aspects of it. This implies that a flexible, yet systemic interpretation of the frameworks introduced by the authors cited above is needed to study OLs. Figure 1 shows a graphical representation of such interpretation.

Activity theory as a framework for office evaluation is further described in Babapour (2019) and is utilised in the study of activity-based flexible offices in the public and private sector. This paper contributes to the development of that approach by studying a combi-office, in an academic setting, and focusing on the interrelations between individual employees, their activities and the spatial attributes of the OL.

\section{Method}

A mixed-method approach was selected for the in-depth study of employees' use of the OL post-relocation, as well as the mediating role that the landscape itself had on such usage. The data collection at the office was carried out between mid-January and early-February 2018, and it involved individual semi-structured interviews with the employees, observations of the OL and the study of documentation concerning the project for the renovation of the building. Additionally, the architect responsible for the renovation of the OL post-relocation was interviewed. The datasets were collected in parallel, analysed separately, and findings were compared, contrasted and integrated (cf. convergent-parallel research design [Creswell, (2014), p.15]).

\subsection{Case study context}

The employees invited to participate in the study belong to a division of a Swedish university. This division, together with another 10, relocated to a renovated building six months before the data collection took place. These employees had policies for flexible work in time and location, as well as duties out of the office, such as teaching or lab work. Before the relocation, most of the study participants worked isolated in cell-rooms or in rooms shared by two colleagues. The planners and the organisation agreed that the main goal for the relocation would be to increase collaboration between employees, as well as with visitors and students on the campus. The plan was to achieve such collaboration by opening the spaces, blending the zones dedicated to employees and students, allocating more floor area for shared and collective uses, and enabling unrestricted access to all zones. However, the initial plan suffered modifications:

1 additional costs during the renovation were compensated with a higher density of desks per room

2 technical issues forced zoning changes, resulting in employees and students sitting on different floors

3 thefts of office equipment shortly after the relocation caused the access to the office to be restricted to employees only. 
The new landscape was a combi-office (cf. Danielsson, 2016) distributed on the three top floors of a renovated six-storey building. The combi-office introduced several changes respect to the former OL, for example, individual rooms disappeared, and employees' desks were in rooms shared by either two or eight colleagues. In addition to the assigned desks in the office rooms, employees had 'backup' spaces, such as phone booths, formal and informal meetings spaces, coffee/lunch lounges, quiet rooms with sofas, flexible and quiet rooms with non-bookable desks, and a rest room. Table 1 provides an overview on the main office spaces addressed in this paper.

Table 1 Description of the room types and number

\begin{tabular}{|c|c|c|c|c|}
\hline \multirow{2}{*}{ Room type } & \multicolumn{3}{|c|}{ Total per floor } & \multirow{2}{*}{ Brief description } \\
\hline & $3 r d$ & 4 th & 5 th & \\
\hline Office rooms* & - & 10 & - & $\begin{array}{l}\text { Rooms with assigned height-adjustable desks, } \\
\text { ergonomic chairs, individual cabinets for storage. } \\
\text { Shelves and coat rack for shared use. Two screens } \\
\text { per desk. The division analysed had office rooms for } \\
\text { two or eight employees. Big window surface towards } \\
\text { the exterior and glass partition towards the corridor. } \\
\text { White walls and restricted customisation. }\end{array}$ \\
\hline Quiet rooms $2 p$ & 3 & 6 & 0 & $\begin{array}{l}\text { Replicate the office rooms for two employees, but desks } \\
\text { are non-bookable and there is no storage. One screen } \\
\text { per desk. Big window surface towards the exterior and } \\
\text { glass partition towards the corridor. White walls and no } \\
\text { decoration. }\end{array}$ \\
\hline Quiet rooms $6 \mathrm{p}$ & 1 & 3 & 0 & $\begin{array}{l}\text { Rooms with six non-bookable workstations distributed } \\
\text { around a rectangular desk surface. Workstations were } \\
\text { delimited with portable felt screens and were equipped } \\
\text { with one screen. Coat rack for shared use. Big window } \\
\text { surface towards an indoor piazza, and glass partitions } \\
\text { towards the corridors. White walls and no decoration. }\end{array}$ \\
\hline $\begin{array}{l}\text { Quiet rooms } \\
\text { with sofas }\end{array}$ & 2 & 1 & 0 & $\begin{array}{l}\text { Rooms with sofas for two-three persons whose layout in } \\
\text { the room was rearranged according to activities and } \\
\text { preferences. Big window surface towards an indoor } \\
\text { piazza, and glass partition towards the corridors. White } \\
\text { walls and no decoration. }\end{array}$ \\
\hline Flexible rooms & 2 & 2 & 0 & $\begin{array}{l}\text { Rooms with six non-bookable desks, ergonomic chairs } \\
\text { and individual non-assigned lockers for part-time } \\
\text { employees and students involved in academic projects. } \\
\text { One screen per desk. Coat rack for shared use. } \\
\text { Big window surface towards an indoor piazza, } \\
\text { and glass partition towards the corridors. } \\
\text { White walls and no decoration. }\end{array}$ \\
\hline Phone booths & 8 & 8 & 0 & $\begin{array}{l}\text { Small rooms with a small height-adjustable desk and a } \\
\text { chair. Glass partitions towards open meeting areas or } \\
\text { coffee lounges. White walls and no decoration. }\end{array}$ \\
\hline $\begin{array}{l}\text { Meeting rooms } \\
4-8 p\end{array}$ & 9 & 9 & 1 & $\begin{array}{l}\text { Rooms with a meeting table and chairs or elevated } \\
\text { meeting tables and stools. Whiteboard, TV screen. } \\
\text { Videoconference cams available in some rooms. } \\
\text { Big window surface towards an indoor piazza, and glass } \\
\text { partition towards open meeting areas or coffee lounges. } \\
\text { White walls and no decoration. }\end{array}$ \\
\hline
\end{tabular}

Note: *Data presented in aggregate form and only include the office rooms of the division participating. 
Table 1 Description of the room types and number (continued)

\begin{tabular}{|c|c|c|c|c|}
\hline \multirow{2}{*}{ Room type } & \multicolumn{3}{|c|}{ Total per floor } & \multirow{2}{*}{ Brief description } \\
\hline & $3 r d$ & $4 t h$ & $5 t h$ & \\
\hline $\begin{array}{l}\text { Meeting rooms } \\
+8 \mathrm{p}\end{array}$ & 4 & 6 & 3 & $\begin{array}{l}\text { Rooms with a big rectangular meeting table or desks } \\
\text { arranged in U shape surrounded by chairs. Whiteboards, } \\
\text { TV screen, beamer. Videoconference cams available in } \\
\text { some rooms. Big window surface towards an indoor } \\
\text { piazza, and glass partition towards the corridor. White } \\
\text { walls and no decoration. }\end{array}$ \\
\hline $\begin{array}{l}\text { Coffee/lunch } \\
\text { lounges }\end{array}$ & 2 & 2 & 1 & $\begin{array}{l}\text { Open spaces with diversity of tables and seating } \\
\text { options, kitchenette and few plants. Open to corridors or } \\
\text { passing areas. Balconies and phone booths are } \\
\text { accessible at some of these lounges. Meeting facilities } \\
\text { available in the surroundings. Big window surface } \\
\text { towards the indoor piazza in all of them, except one } \\
\text { (the biggest on the top floor) that faces the exterior. }\end{array}$ \\
\hline Balconies & 2 & 2 & 1 & $\begin{array}{l}\text { Outdoor terrace on the fifth floor, with tables and seats } \\
\text { and connected to the coffee/lunch lounge. Smaller } \\
\text { balconies with few low stools. }\end{array}$ \\
\hline
\end{tabular}

Note: *Data presented in aggregate form and only include the office rooms of the division participating.

Figure 2 Left: corridor at the former OL and corresponding fragment of the floorplan; right: meeting area at the new OL and corresponding fragment of the floorplan (see online version for colours)
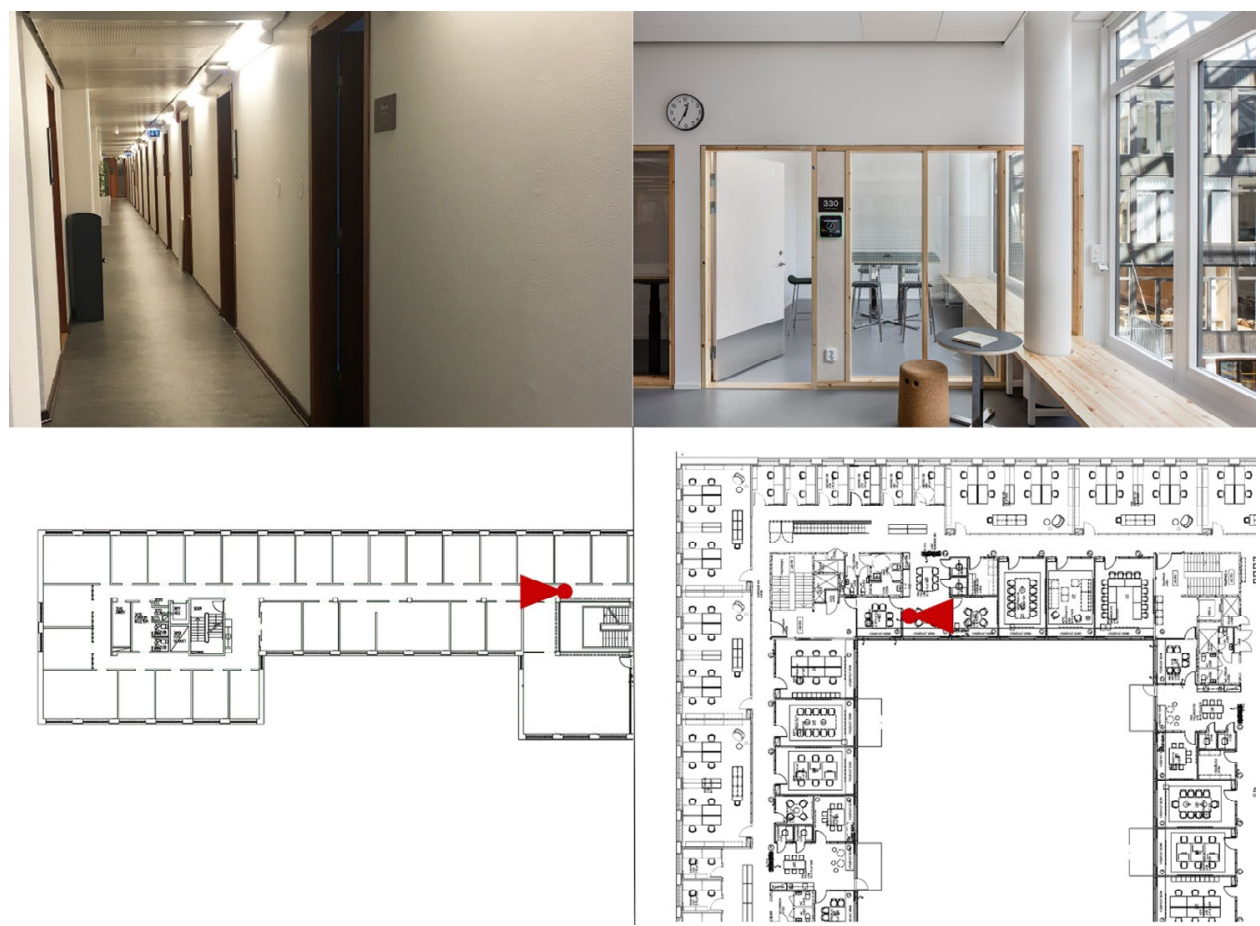
Pictures and floorplans of the OLs pre- and post-relocation are shown in Figure 2.

The studied OL had 260 assigned desks, of which 42 were allocated to the division participating in the study. During the data collection 36 of the division employees were working full-time and had an assigned desk. Those who were not working at the office on a regular basis or had no assigned desks, e.g., part-time workers and guest researchers, were excluded from the study.

\subsection{Informants}

Information about the case study and the sign-up process was distributed via e-mail and brochures. A total of 16 employees volunteered as informants and their participation was rewarded with cinema tickets. Table 2 displays demographic data of the employees invited and of the sub-sample who signed up for the interviews. The representativeness of the sample was considered satisfactory, despite the gender unevenness, as this is in line with the underrepresentation of women in Science, Technology, Engineering and Math (STEM) (e.g., Landivar, 2013).

In order to gain an additional perspective on the case studied, the leading architect of the building's renovation project was also interviewed.

Table 2 Demographics and representativeness of the sample

\begin{tabular}{lcc}
\hline & Total invited $(n=36)$ & Informants $(n=16)$ \\
\hline Female & $8($ or $20 \%)$ & $5($ or $31 \%)$ \\
Male & $28($ or $80 \%)$ & 11 (or 69\%) \\
Researcher & 21 & 11 \\
Professor/lecturer & 10 & 4 \\
Project assistant & 1 & 1 \\
Other categories (e.g., project manager, admin.) & 4 & 0 \\
Age (years); (average) & n.a. & $27-57$ (mean $=34.8)$ \\
\hline
\end{tabular}

\subsection{Data collection}

The interviews with the employees were conducted in meeting rooms at the refurbished office. Interviews lasted for approximately one hour and were audio recorded with the consent of the informants. During the interviews, the informants were guided through a series of themes chosen to allow them to reflect and elaborate on their daily routines at the office, their criteria for using different spaces and artefacts, insights on spatial attributes supporting or hindering their activities and preferences, perception of changes post-relocation, and contextual aspects of the social work environment, the organisation, the relocation process and personal matters (see the interview guide in Table 4, Appendix). The particular selection of themes and questions is justified by the need to gain a deeper understanding of the diverse interrelations between employees, their activities, the OL and its attributes, and the case-specific circumstances. These themes intend to cover each of the interrelated elements from an employee perspective. Informants were also provided with materials, such as floorplans, markers, sticky notes and charts to be used as mediation tools (cf. Karlsson, 1996) to trigger reflection and 
verbalisation on details of their experiences in relation to the OL. Figure 3 displays some of the material used during the interviews.

The observations included 19 rounds, i.e., a predefined path throughout the office was followed and notes were taken at each of a series of checkpoints. The rounds were carried out at different times of the day, i.e., once between $8 \mathrm{~h}$ and $10 \mathrm{~h}$, once between $10 \mathrm{~h}$ and $12 \mathrm{~h}$, once between $13 \mathrm{~h}$ and $15 \mathrm{~h}$ and once between $15 \mathrm{~h}$ and $17 \mathrm{~h}$. Times varied slightly for every round and the order in which the floors were visited was also altered, in order to spread more evenly the timeslots for observations along the day. The equivalent of a regular Monday-to-Friday working week was documented by scheduling observations rounds on 17th, 18th, 19th, 22nd, 23rd, 26th, 29th, 30th and 31st January, according to the availability of the observer and avoiding two events at the office studied that were not part of the regular routines and caused abnormal occupancy rates. The employees were aware of the observer's activity. Data on occupancy, available facilities and equipment, activity patterns and flows of people between spaces was gathered. Up to 121 points were observed on a single round, but spaces such as open meeting areas along the corridors, service rooms, reception, stairwells, etc., were excluded from the analysis because these were used as transition/passing areas. The nap room was also excluded because it was lacking curtains and therefore it was considered not to be fully operative.

Figure 3 Mediation tools (see online version for colours)

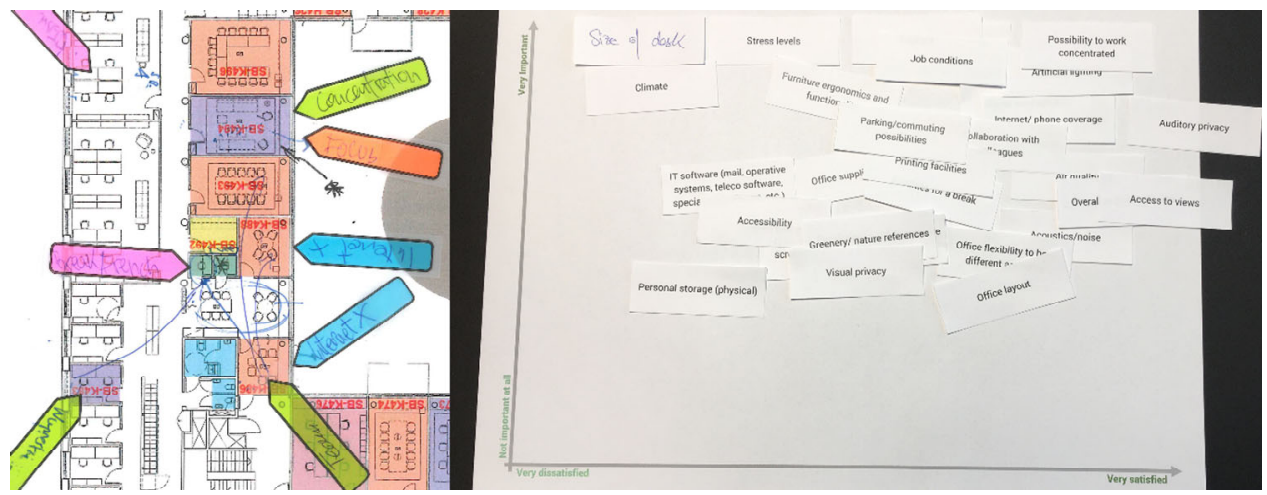

Notes: Left: informants' notes on floorplans and right: labels sorted on a chart about satisfaction levels, horizontal axis, and importance, vertical axis (see Table 4, workspace support)

The preliminary findings from the interviews with the informants and the observations were presented to the division of employees to get feedback and confirmation.

In addition, the architect was interviewed at her workplace and the questions posed concerned the renovation process, planners' intentions regarding the use of the OL, specific circumstances of the case, and the bureau's general approach to office developments.

\subsection{Data analysis}

The audio files from the interviews were transcribed using Microsoft Word, and their contents were analysed using the software NVivo11. Each transcript was reviewed in 
detail and informants' insights were coded inductively into 'nodes' that relate to general patterns and topics, e.g., work routines, activities, personal and functional criteria for choosing spaces, etc. Over 90 nodes were listed as a result of the coding process. A relevant example was the node 'meetings and group work', in which 36 instances from 15 informants were identified that elaborated on informants' meeting routines. These instances were utilised to study the use of meeting rooms. Informants' answers were also compared to identify convergences and divergences in the way that the informants experienced the context of the relocation to the new landscape. The topics and patterns identified were grouped into themes, and these were further analysed taking the framework as a reference. A set of spatial attributes was identified that employees most recurrently related to matches and mismatches, and therefore were of influence in the use of the landscape. Finally, this analysis, together with the notes from the interview with the architect, the study of project documentation and the field notes from the observations were contrasted, compared and integrated.

In order to ensure the quality of the conclusions, the research approach involved the following strategies (cf. Miles and Huberman, 1994):

1 method triangulation and integration of diverse data sources into the analysis

2 gathering of informants' feedback to confirm the findings

3 presenting context-rich and transparent narratives of the case and its context, the research and methodological approaches, the analytical steps followed and the findings.

\section{Findings}

The findings are structured in three sections: the first section describes the observed occupancy and usage of the OL (RQ1); the second explains the landscape use from the informants' perspective in relation to the matches and mismatches between their activities and the OL mediating (RQ2); the third one concerns the interview with the architect and it provides further insight on the case context and the rationale behind the office use (RQs1 and 2). The main findings are reported by room type, following the order presented in Table 2 .

\subsection{Occupancy and usage of the $O L$}

Table 3 summarises the results from the observations. Information on occupancy is presented in two modes:

1 the percentage of seats occupied in relation to the maximum capacity of the space

2 the percentage of times that spaces were observed to be in use with respect to the total number of observations rounds.

Given that the division of employees studied was located on the 4th floor, data corresponding to this floor only is also displayed.

Overall, the occupancy of the OL was low, especially in quiet rooms, implying that the availability of backup spaces was high. Open meeting spaces and the reception on the third floor remained as passing areas. These observations corresponded to informants' 
perceptions: "my experience when I walk around is that there are a lot of empty spots (referring to flexible, quiet and meeting rooms)" (I10).

The average occupancy of office rooms varied substantially throughout the day. In the mornings the occupancy was the lowest $(<20 \%)$, growing gradually until lunch time. After lunch, the occupancy was the highest $(\sim 40 \%)$ and it slightly decreased throughout the afternoon.

Table 3 OL use by occupancy and recurrence

\begin{tabular}{|c|c|c|c|c|}
\hline Room type & $\begin{array}{c}\text { Average } \\
\text { occupancy }^{1} \\
\text { (\%) }\end{array}$ & $\begin{array}{c}\text { Average } \\
\text { occupancy } 4 \text { th } \\
\text { floor only }^{1}(\%)\end{array}$ & $\begin{array}{c}\text { Space in } u s e^{2} \\
(\%)\end{array}$ & $\begin{array}{l}\text { Space in use } \\
\text { 4th floor only } \\
\text { (\%) }\end{array}$ \\
\hline Office rooms & $31.4 *$ & - & $58.4 *$ & - \\
\hline Quiet rooms $2 p$ & 8.1 & 6.8 & 15 & 13.7 \\
\hline Quiet rooms 6p & 1.8 & 0 & 7.6 & 0 \\
\hline Quiet rooms with sofas & - & - & 19.5 & 15.8 \\
\hline Flexible rooms & 10.8 & 11 & 52.7 & 44.7 \\
\hline Phone booths & 9.1 & 6.6 & 9.1 & 6.6 \\
\hline Meeting rooms $4-8 p$ & $38.9 * *$ & $36.2 * *$ & 28.7 & 30.3 \\
\hline Meeting rooms $+8 p$ & $40.6^{* *}$ & $37.7 * *$ & 31.8 & 26.3 \\
\hline Coffee lounges & - & - & 26.1 & 23.7 \\
\hline Lounge 5th floor & - & - & 94.4 & - \\
\hline
\end{tabular}

Notes: ${ }^{1}$ Percentage of seats occupied with respect to the maximum room capacity.

${ }^{2}$ Percentage of times that the spaces were in use during the observation rounds.

*Results are presented in aggregate form and only include the office rooms of the division participating.

**Percentage of seats occupied in the rooms in use.

The quiet rooms were either empty or were seldom used during the study. When these were used, flexible and quiet rooms were often occupied by a single person carrying out own work.

A total of 184 meetings were observed. The duration (traceable when planning meetings through the booking system) and number of participants in these interactive/ group work activities was also noted. Figure 4 displays the occupancy of all the meeting rooms in the office and indicates that some meeting rooms were preferred over others. The empty areas in Figure 4 show the periods of the day in which particular rooms were never observed to be in use during the study, while the coloured areas show the periods of the day in which particular rooms were observed to be in use; the darker the colour, the more frequent were the meetings in a room at a specific time of the day. The rush hours for meeting rooms were between $10 \mathrm{AM}$ and 12 noon (grey column). The meeting rooms on the 3rd and 5th floors tended to be busier, but those floors had fewer meeting rooms than on the 4th floor. Furthermore, the meeting rooms on the 5th floor, except for one, were accessible to people outside the department and were often booked for longer sessions.

The lounge on the top floor was frequently visited throughout the day for, e.g., breaks, socialising with colleagues or informal meetings, but its occupancy had extreme variations: during peak hours, more than 60 employees could share this space for the lunch break, while in trough hours there were one to four employees having a coffee 
break, socialising, or sitting alone while reading or relaxing. The coffee lounges on the 3rd and 4th floors were regularly used by individuals and small groups for quick breaks.

Figure 4 Occupancy of meeting rooms (see online version for colours)

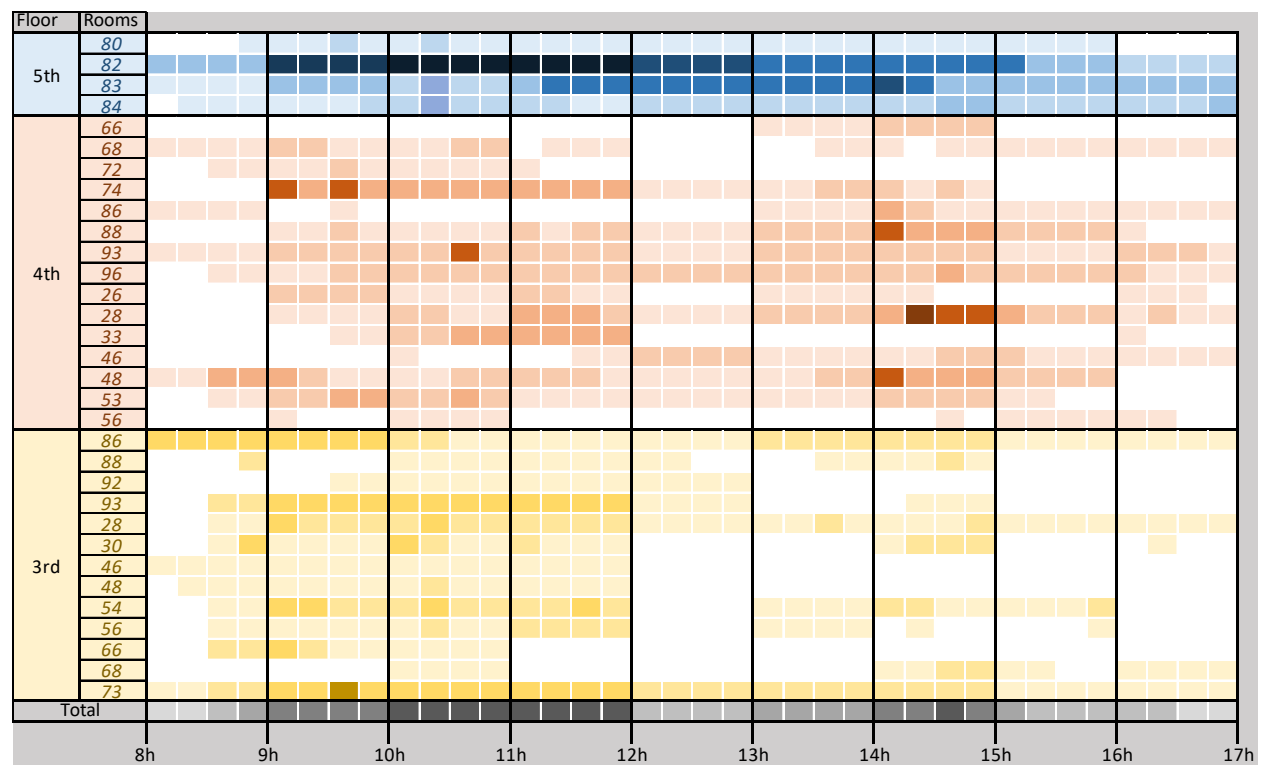

Notes: The darker the colour, the more frequent were meetings at a time of the day.

Time of the day on the horizontal axis; meeting rooms on the vertical axis.

\subsection{Spatial attributes and activities in relation to landscape use}

The perception of most of the informants (15/16) was that the new OL was more flexible and capable of hosting more activities compared to the landscape before the relocation. "It was not nice for my colleague to listen to my Skype calls (at the former OL). [...] Now I can leave (and use the phone booths) so I do not distract him" (I1).

The workstations in the office rooms were indicated by the informants as one of their favourite spots in the office (the other was the lounge on the top floor) and the place where they preferred to do their individual work. Matches and mismatches between employee's needs and preferences, their activities, and the office rooms (understood as a constellation of attributes and properties) where identified. Among the matches were:

- The spatial attribute of daylight matched the preferences of the informants because of its abundance. "[It is] super important and I am almost fully satisfied $[\ldots]$ [the only problem is that] right now the automatic blinds don't work [as they should]" (I10).

- The ability to accommodate more colleagues per office room was an attribute that matched the individual preference for larger social groups than before the relocation. "Sharing the room with only one person means that if it is not a $100 \%$ match, you don't have any social interaction for the whole day. [...] [This was the case at the former office and] it was worse than being alone" (I2). 
- The layout was a spatial attribute that matched informants' preferences due to the proximity of the office rooms to other spaces, such as the coffee lounge and meeting rooms. "I have a fantastic place, $[. .$.$] coffee, phone booths, larger meeting rooms,$ smaller ones... [everything is close by]" (I8).

- The activities carried out individually, such as reading or writing, were supported by two properties of the desks:

a They were assigned, "[I like my desk] because it is my place." (I1), "We have our own desks, so we are not moving around that much" (I7).

b They were height-adjustable, "I always wanted one of those tables that you could adjust the height" (I13).

- Having two screens per workstation was an attribute identified as matching the needs and preferences of several informants. "I have two screens and that is super important for me. It gives me a good feeling to work" (I3).

Mismatches were also reported:

- The glass partitions between the rooms and the corridors were perceived as an attribute causing more visual distraction than in the former OL, where partitions were brick walls. A minority also reported lack of privacy with regard to this attribute. "I see some people put screens to block the view of their desktop, or not being disturbed by people walking by [...]. You cannot really block what is happening around you" (I11).

- The ability to accommodate more colleagues per office room was also identified as a mismatch for several informants, since they were exposed to more distraction while working on their own. In addition, there were no explicit rules on how to behave. "If you are sitting with other people, it is not an easy thing to imagine you are alone [...] phone calls, chatting and the movement of other people" (I14).

Attributes such as the ability to accommodate more colleagues per room, or the glass partitions, are connected to the social nature of offices. In this regard, visual distractions, noise issues, lack of privacy, etc., clearly indicate that the activities carried out in the office rooms were influenced by a strong interrelation between the individual and the collective dimensions of the activity system. This situation was less evident in the former OL where the degree of seclusion of rooms and workstations was higher. Nonetheless, informant's perceptions on noise as a hinder for own work were not unanimous, since the exposure to noise varied from room to room. "We have a very quiet room, I think. We have a lot of people who are not there all the time [...]. It's unnecessary to have any rules" (I12). Moreover, employees could order noise-cancelling headphones, some informants were "not easily bothered", and others were becoming used to the visual exposure caused by the glass partitions.

Quiet rooms, especially those with six desks, represented an alternative constellation to office rooms intended to support own work and concentration. Yet, these remained unused during the whole study. Important differences observed between the quiet rooms with six desks and the office rooms help to explain why the office rooms were preferred for individual work, even if such work required high concentration, e.g., reading/writing scientific reports. 
- Quiet rooms had shared desks instead of assigned desks, and they were not bookable. These two properties were identified as mismatches, since carrying belongings such as computer, books, printed documents, etc., was perceived as an extra action for everyday activities: "carrying my stuff to other rooms would just make more work so to speak [...]. I don't like to run all over the place. I like my place and stay there" (I4).

- Other properties of the desks in quiet rooms that help to explain the underusage of these rooms were: their small size, poor separation with small portable felt screens, and impossibility to adjust their height. These properties could lead to mismatches with individuals' preferences.

- The lack of storage was a spatial attribute identified as a mismatch for the informants' need of leaving their belongings in place and safe.

- Some properties of the chairs available in this type of room were also identified as potential mismatches with informants' preferences, for example the padding was stiff and non-perspirable, and the ergonomic adjustments were limited.

- Quiet rooms had one screen per workstation instead of the two in office rooms.

- The smaller quiet rooms were a better match for individual preferences and activities that required concentration. They had the same furniture as in the office rooms and more daylight, due to the windows that faced the external facade instead of an indoor piazza.

Another type of quiet room had sofas and a whiteboard, which in principle should have been good matches for individual activities such as reading, or group activities such as informal meetings. However, informants identified the attributes of temperature and aesthetic design as being cold and uninviting; sofas had the property of being too stiff to match long reading sessions, the placement of the whiteboard behind the sofas made them less usable, and floor-to-ceiling glass openings made anyone sitting there feel exposed.

In this case, the glass openings and partitions highlight once again the existing link between the individual and collective dimension of activities. Moreover, informants contributed to the low occupancy of quiet rooms with their social norms and practises: "if you see someone working there, then you don't go inside to respect the privacy of this person" (I15). Moreover, an informant expressed the feeling of having to excuse oneself for not staying at one's desk. "I got questions from colleagues in my room like, "was it too loud today that you were sitting here? Sorry." And I say, "no, I just need to concentrate." [...] I felt that I had to answer questions [when moving somewhere else]." (I15). Such feelings were coherent with the opinion expressed by another informant: "I'm always very sceptical about people who say that they are working from home. I doubt what they are actually doing" (I16).

According to the informants, the reconversion of unused spaces like these to other uses would solve some of the mentioned mismatches by making the landscape more supportive for their activities and closer to their needs and preferences: "I suggested that we could make it (an unused quiet room) into library to give it a function and make it cosier" (I6). 
Phone booths had the property of being small and were perceived as cramped. This, together with white walls and lack of decor made them unappealing. Meeting rooms close by were often available and seen as a better match for individual preferences when using Skype or the phone. Anyhow, phone calls were often short, which made them harder to be observed and further explain the low occupancy of phone booths.

Meeting rooms were perceived as a clear upgrade for interactive and group work after the relocation, although a few details, such as the installation of power outlets in the tables, were incomplete. The main attributes matching the informants' meeting routines and preferences were the variety of rooms and equipment: "we have good meeting facilities here. The number and the equipment [...] and variating size" (I7). The criteria to book them were primarily proximity to their desks and the number of participants in the meeting. However, eventual needs of extra space and preferences regarding equipment or a nicer background were prioritised over the number of participants. Thus, meeting rooms were rarely occupied to their maximum capacity. Instead, bigger rooms were chosen: "if I am going to have a video meeting, I prefer to have a better environment (than in the phone booths) for the partners to see" (I14). In other words, the collective element of meeting activities played an important role in the use of meeting rooms, but informants' choices were ultimately driven by a strong relation between meeting rooms and personal needs and preferences. On the other hand, a few small meeting rooms were underused due to a mismatch between individual preferences and the lack of windows.

The lounge on the 5th floor and the balconies were recurrently indicated as favourite spaces. Explanations for this were:

- The match between preferences and a constellation of attributes in the lounge such as aesthetic appeal, abundant daylight, and furniture settings that fostered socialisation: "it is beautiful. I like it" (I3). "It is bright and nicely furnished, and it makes it easy to meet people if you just want to discuss" (I6). "I have found many new friends $[\ldots]$. I remember the first or the second month that we went to this balcony $[\ldots]$. But recently all of us are going up to the lunch room (lounge) for coffee" (I9).

- The views from the balconies were perceived as enjoyable and matched the need for a break: "I like the balconies as well [...]. Sometimes I go out and look at what they are doing down on the ground floor, if there is an exhibition or something going on" (I11).

Moreover, between the coffee breaks and lunchtime, individuals and small groups were observed working in the lounge as if this space had become their real 'quiet room'. It seemed that the quiet rooms were a poorer version of their office rooms, while the lounge provided a more noticeable change of setting that better matched their preferences.

Finally, the availability of smaller coffee lounges on the other floors and the glass partitions between spaces were two attributes that facilitated more encounters between colleagues and more daylight than in the former OL. These attributes matched the informants' preferences on a collective level: "[the former office] was very depressing, very dark, long corridors, everything was closed. You couldn't see anyone in the rooms because everyone had the doors closed and everything was very closed. Now it's much more open. I like that" (I11). Informants also indicated that the frequent encounters resulted in more social interaction: "colleagues walk by and show their coffee mug 
[to call for a break through the glass]" (I12). Figure 5 compiles the main matches and mismatches found between the employees, their activities, and the OL within the analysed context.

Figure 5 Activity theory system perspective on the main matches and mismatches found (see online version for colours)

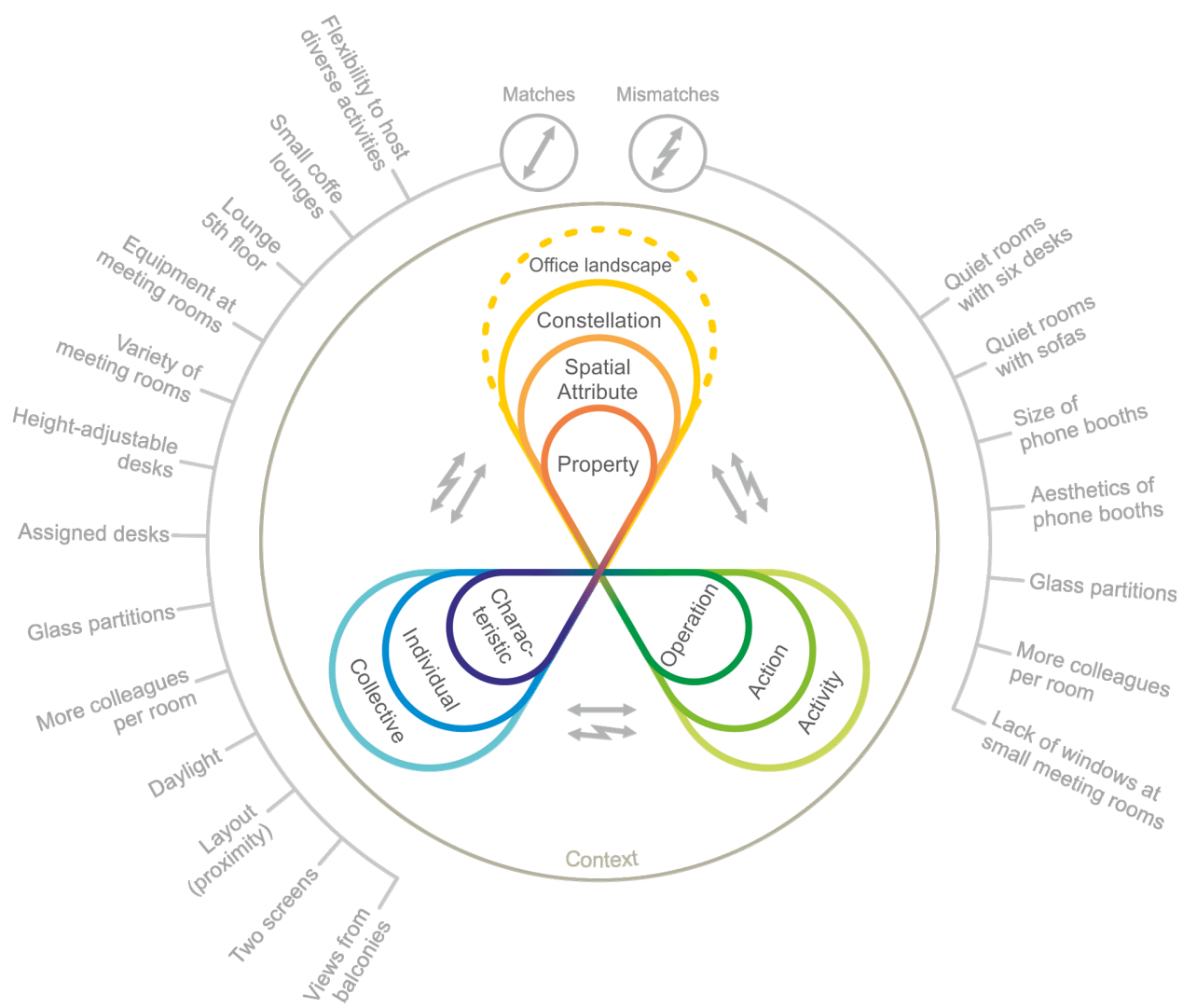

\subsection{Architect's perspective on the relocation process and the intended use of the $O L$}

The interview with the architect provided with information about the relocation process and the overall context of the case studied (see also Section 3.1). This interview contributed with an additional point of view that further explains how employees were using the OL and why.

According to the architect, the organisation and the facility owner had been discussing the renovation of the building where the new office is located for years, so the planners had abundant information and some instructions from the beginning. Before the relocation took place, a consultancy company surveyed employees about their needs and preferences, and representatives of the different divisions relocating to the new office were invited to meetings and workshops were the planning was discussed. Later in the 
process, employees were invited to visit few prototypes of the office rooms to give feedback on the preferred furnishing options and the overall setup of the office rooms.

However, the architect had no record on the extent to which the information collected by the consultants was actually utilised. Moreover, the architect reported that in the case of the employees sitting on the 4th floor, the main design decisions were often made top-down, and the real influence that employees had in the process was limited. This situation contributes to the explanation of two relevant aspects from the findings:

1 Increased socialisation instead of intended collaboration: the design decisions taken in the planning of the OL post-relocation to increase collaboration by fostering personal encounters, had the unintended effect of increasing social interaction instead of collaboration. The main reason given by the informants was that their activities were mostly related to individual work on unrelated topics: "there are no real collaborations [...]. We don't work (do research) on the same subject, but we can actually talk to each other" (I5).

2 Underused spaces: although the overall perception of employees about the new OL was positive, these discussed informally about proposals to reconvert underused/ disused spaces. According to the architect, some of the proposals were manifested in the planning process by the employees, for example, a small library, but these did not go through. Also, the architect acknowledged that post-relocation evaluations are very valuable to revise unintended results, but in general "companies in the building sector rarely allocate resources to evaluate the buildings built."

\section{Discussion}

The findings of this study revealed several interrelations between the use that employees make of their OL after a relocation, and the spatial attributes existing in the OL. Overall, informants perceived that the new landscape was more flexible and suitable than the former landscape to host diverse activities at hand. In all cases, informants established clear connections between their activities, what they needed and preferred to carry them out, and what the new landscape enabled. Matches and mismatches were identified in this regard that help to explain the use of the different rooms.

The visual openness created by the glass partitions, together with the multiple spaces for breaks, facilitated the encounters and interaction between employees. However, a key finding was that these spatial attributes primarily matched a more active social environment, but not interpersonal collaboration as intended by the planners and the organisation. Informants reported that they were mostly working individually on subjects unrelated to those of their colleagues, so their collaboration was limited. Discrepancies on the outcomes of open spaces and communication have also been found in previous studies (Bernstein and Turban, 2018; De Croon et al., 2005; Kim and De Dear, 2013). The fact that an OL enables the possibility to collaborate does not mean that individual users will automatically engage in such collective activity. This situation also corroborates the findings of previous research (De Bruyne and Beijer, 2015; Greene and Myerson, 2011; Mateo-Cecilia et al., 2018; Soriano et al., 2018), which underlines the importance of analysing the activity patterns and preferences of employees before a spatial intervention. 
Remarkably, the glass partitions were also responsible for more visual distraction and less privacy. This is coherent with previous studies associating open landscapes to perceptions of lack of control over the environment (e.g., Kim and De Dear, 2013). Hence, this study shows that a concrete spatial attribute can be responsible for both matches and mismatches with employee activities and preferences. Additionally, a practical implication of introducing spatial attributes, such as glass partitions in the landscape, would be the need to consider the interrelation between the individual and social dimensions and its potential side effects, alongside the goals for the office relocation. Understanding and preventing those side effects would reduce the need for additional post-relocation interventions.

Another key finding was that informants found it more convenient to work at their own desks, regardless of the task at hand, or even if the level of concentration needed made it more logical to use a different space. Several informants reported that they were not easily disturbed by noise or perceived the office rooms as quiet enough - the low occupancy contributed to this. Others managed the auditory exposure with headphones, i.e., through a compensatory behaviour (cf. Acun and Yilmazer, 2018). Exceptionally, a few informants preferred to work from home occasionally to find the concentration and privacy needed. This indicates that a majority perceive switching to a different workstation as a bigger burden than remaining at the desk and dealing with occasional distractions. These findings are comparable with other investigations on flexible work environments and the commitment of employees to flexible working (Babapour and Rolfö, 2018; Cobaleda-Cordero and Babapour, 2017; Hirst, 2011). These studies found that the majority of employees tended to settle at a desk, in order to satisfy needs and preferences that were not always related to the task at hand. The implications of this are:

1 backup spaces must offer a truly differentiated and optimal experience of use to motivate employees to use them

2 the implementation of flexible working must be complemented with changes in organisational processes and work routines to be effective.

A consequence of employees choosing their desks for individual work was that quiet rooms were rarely or never used. Particularly, quiet rooms with six desks were interpreted as a worse equipped version of office rooms, but informants' insights were here based on anticipated or projected matches and mismatches; none of them were actively using these rooms but they had opinions and expectations on what it would be like to work in those rooms. Such situations, together with the predisposition of informants to deal with occasional distractions at their desks, made these quiet rooms somehow meaningless. This contradicts the studies on offices for flexible working where employees shared a number of spaces for interaction and quiet rooms were found necessary for employees to work in a concentrated way and to be satisfied with the office (Haapakangas et al., 2018; Rolfö et al., 2018). The latter cases do not correspond to university settings, but still share need for concentration. In fact, the need for concentration among university employees seems to be rather high in comparison to other sectors (Berthelsen et al., 2018), which makes even more remarkable the underuse of quiet rooms in the case studied. However, in this case, both the informants and the architect confirmed that employees' opportunities to make their needs and opinions heard in the planning process had been limited. This contextual aspect of the relocation helps to understand the identified mismatches between employees and quiet rooms, and therefore 
further explain why these rooms were underused. Each organisation is unique and requires a customised landscape solution (Van Koetsveld and Kamperman, 2011). Therefore, actively involving employees when planning relocations into a new landscape is vital to increase the likelihood of matching employees' activities and preferences (Babapour and Rolfö, 2018; Hongisto et al., 2016; Lahtinen et al., 2015; Vink et al., 2006; Vischer, 2008). Moreover, previous studies evaluating office use stress the importance of evaluating the projects delivered in the building sector from a user perspective to feed forward to subsequent interventions (Hansen et al., 2011; Lindahl et al., 2012). Nevertheless, Lindahl et al. (2012) highlight that practitioners' praxis often disregard post-occupancy evaluations, and the architect interviewed confirmed that practitioners are aware of this need, but usually little or no resources are allocated to it. The implication of this is that opportunities for innovation and optimisation of resources in the building sector are neglected. Unused or underused conditioned spaces represent unnecessary operational costs and environmental impact (Economidou et al., 2011). Likewise, unintended uses of an OL by the employees can impact negatively the financial and environmental performance of buildings (Haldi and Robinson, 2011; Windlinger et al., 2012) and, subsequently, of organisations.

In any case, beyond informants' activities and preferences justifying their use of the landscape, it seems that employees may also be reproducing - or at least trying - the same behavioural patterns that they had at the former OL. Before the relocation, the informants were doing most of their work in their rooms mainly because of the absence of backup spaces. Therefore, those patterns were part of their individual repertoire of action possibilities. This is aligned with the studies in facility management (Alexander, 2010; Fenker, 2008; Windlinger et al., 2015) where offices as instruments are evaluated from a usability perspective. Interestingly, from this perspective the matches and mismatches between the instrument (i.e., an artefact in use) and the activity could be related to studies of office functionality, i.e., whether the instrument fulfils the function that it is designed for. Similarly, the matches and mismatches between the instrument and the subject could be related to the study of office ease-of-use and user satisfaction.

The activity-theoretical approach in this paper and the usability approach in facility management differ in their theoretical grounds, but both approaches allow similar broad conclusions to be drawn:

1 offices do influence employees' ability and will to perform (Lindahl et al., 2012)

2 employees' insights, experiences and context are vital for the planning, operation and evaluation of offices (Hansen et al., 2011).

The added value of activity theory is the possibility to investigate the matches and mismatches between employees, activities, OLs and context from a systemic perspective, while considering multiple levels of abstraction (operation, action, activity; property, spatial attribute, constellation; characteristic, individual, collective) that enable great depth of analysis. This represents an opportunity for organisations to further optimise the evaluation, development and operation of OLs that impact positively on employee satisfaction and productivity and, by extension, on society.

Practical implications and limitations were identified in the study that are worth mentioning. Firstly, the size of the sample and the qualitative data collected limit the extent to which results can be generalised (cf. Creswell, 2014). However, mix-method studies addressing the use of OLs in depth are few. This paper contributes to the literature 
with rich insights on employee perceptions about the use of a landscape for flexible working that in this case corresponds to a combi-office. Secondly, the triangulation of diverse data sources was crucial to crosscheck informants' insights and increase the reliability of the findings. Finally, the findings presented in this paper show that relocations are complex processes that might require post-occupancy adjustments. Moreover, recent longitudinal studies (Von Behren et al., 2018; Bergström et al., 2015; Gerdenitsch et al., 2018; Nijp et al., 2016) show that the changes following a relocation (e.g., satisfaction levels and work routines), although notable, can develop in different directions. Therefore, longitudinal studies investigating the relation between office use and spatial attributes over time would be of great value and prevent seasonal or novelty effects that a single post-relocation study may imply.

\section{Conclusions}

This study investigated the use of a combi-office and the interrelations between the employees, their activities and the OL. Office rooms, some of the meeting rooms and coffee lounges were among the most used spaces, although their average occupancy was low - around a third of the total capacity. Other backup spaces, such as quiet rooms, remained underused.

To describe the interrelations between employees, their activities and the OL, matches and mismatches were identified. For example, the desks in the office rooms were matching preferences because of their height-adjustability and the property of being assigned instead of shared. In addition to preferences, other matches were reported between the landscape and individuals' activities. For instance, having two screens per desk for individual work, or a good diversity of meeting rooms to host different types of meetings. Furthermore, individual preferences for social-related activities were matched by the landscape's ability to accommodate more colleagues per room, the diverse spaces for breaks and the glass partitions between spaces. All these attributes together made it easier to find colleagues and enabled more frequent encounters than before the relocation.

Some of the attributes that matched individuals' preferences were however reported as mismatches impeding individuals' activities. For example, the main mismatches that hampered activities requiring concentration concerned: the landscape's ability to accommodate more colleagues per room that exposed individuals to more noise, and the glass partitions between spaces that led to more visual distraction and less privacy than in the former OL. In this regard, quiet rooms were available but overall were underused due to diverse mismatches, for example between individuals' preferences and stiff seats, or between the non-bookable workstations and the extra action of carrying belongings from one room to another.

The application of the activity theory framework enabled an in depth understanding of the OL in use, as it allowed to systematically analyse employees activities in the OL in relation to:

1 their needs, preferences and action possibilities (e.g., match between employees and assigned desks for own work)

2 the mediating 'artefacts' covering the full span from a constellation of spatial attributes (e.g., office rooms) to the particular property of a spatial attribute (e.g., the height-adjustability of desks) 
3 the context of the case studied (e.g., increase in socialisation as a side effect of design decisions).

This framework provides a systemic perspective on employees' activities and it is recommended to further analyse employees' interactions with their physical office environments.

\section{Acknowledgements}

This research was partly funded by Formas, the Swedish governmental research council for sustainable development. The case study presented here builds on previous research work carried out within the project Smart and Sustainable Offices (SSO). The authors of this paper thank the participants for the time and insights so generously shared.

\section{References}

Acun, V. and Yilmazer, S. (2018) 'A grounded theory approach to investigate the perceived soundscape of open-plan offices', Applied Acoustics, 18 October 2017, Vol. 131, pp.28-37.

Alexander, K. (2010) Usability of Workplaces - Phase 3 [online] https://www.researchgate.net/ profile/Keith_Alexander4/publication/264629107_Usability_of workplaces _Phase_3/links/53ea25290cf2dc24b3cb0d74.pdf (accessed 28 February 2020).

Appel-Meulenbroek, R., Janssen, I. and Groenen, P. (2011) 'An end-user's perspective on activity-based office concepts', Journal of Corporate Real Estate, Vol. 13, No. 2, pp.122-135.

Appel-Meulenbroek, R., Kemperman, A., Kleijn, M. and Hendriks, E. (2015) 'To use or not to use: which type of property should you choose?', Journal of Property Investment \& Finance, Vol. 33, No. 4, pp.320-336.

Babapour, M. (2019) The Quest for the Room of Requirement Why Some Activity-Based Flexible Offices Work While Others Do Not, Chalmers University of Technology [online] https://doi.org/10.13140/RG.2.2.21179.87849.

Babapour, M. and Rolfö, L. (2018) 'Policies in activity-based flexible offices - 'I am sloppy with clean-desking. We don't really know the rules.', Ergonomics, Vol. 62, No. 1, pp.1-20.

Bergström, J., Miller, M. and Horneij, E. (2015) 'Work environment perceptions following relocation to open-plan offices: a twelve-month longitudinal study', Work, Vol. 50, No. 2, pp.221-228.

Bernstein, E.S. and Turban, S. (2018) 'The impact of the 'open' workspace on human collaboration', Philosophical Transactions of the Royal Society B: Biological Sciences, Vol. 373, No. 1753 [online] https://doi.org/10.1098/rstb.2017.0239.

Berthelsen, H., Muhonen, T. and Toivanen, S. (2018) 'What happens to the physical and psychosocial work environment when activity-based offices are introduced into academia?', Journal of Corporate Real Estate, Vol. 20, No. 4, pp.230-243.

Bødker, S. and Klokmose, C.N. (2011) 'The human-artifact model: an activity theoretical approach to artifact ecologies', Human-Computer Interaction, Vol. 26, No. 4, pp.315-371.

Brunia, S., De Been, I. and Van Der Voordt, T.J.M. (2016) 'Accommodating new ways of working: lessons from best practices and worst cases', Journal of Corporate Real Estate, Vol. 18, No. 1, pp.30-47, Emerald Group Publishing Ltd.

Caplan, R.D. (1987) 'Person-environment fit theory and organizations: commensurate dimensions, time perspectives, and mechanisms', Journal of Vocational Behavior, Vol. 31, No. 3, pp. 248-267. 
Cobaleda-Cordero, A. and Babapour, M. (2017) (2017) 'Discrepancies between intended and actual use in activity-based flexible offices - a literature review', 'Joy at Work' Nordic Ergonomics Society Conference Proceedings, NES2017, Lund, Sweden, 20-23 August, p.56.

Creswell, J.W. (2014) Research Design: Qualitative, Quantitative, and Mixed Methods Approaches, 4th ed., edited by J.W. Creswell, SAGE Publications, Inc., https://doi.org/10.1007/s13398-014-0173-7.2.

Danielsson, C.B. (2016) 'Office type's association to employees' welfare: three studies', Work, Vol. 54, No. 4, pp.779-790.

Danielsson, C.B. and Bodin, L. (2008) 'Office type in relation to health, well-being, and job satisfaction among employees', Environment and Behavior, Vol. 40, No. 5, pp.636-668.

De Been, I. and Beijer, M. (2014) 'The influence of office type on satisfaction and perceived productivity support', Journal of Facilities Management, Vol. 12, No. 2, pp.142-157.

De Bruyne, E. and Beijer, M. (2015) 'Calculating NWoW offce space with the PACT model', Journal of Corporate Real Estate, Vol. 17, No. 2, pp.122-133.

De Croon, E.M., Sluiter, J.K., Kuijer, P.P.F.M. and Frings-Dresen, M.H.W. (2005) 'The effect of office concepts on worker health and performance: a systematic review of the literature', Ergonomics, Vol. 48, No. 2, pp.119-134.

Economidou, M., Laustsen, J., Ruyssevelt, P. and Staniaszek, D. (2011) Europe's Buildings under the Microscope [online] https://doi.org/ISBN: 9789491143014.

Edwards, J.R., Cable, D.M., Williamson, I.O., Lambert, L.S. and Shipp, A.J. (2006) 'The phenomenology of fit: linking the person and environment to the subjective experience of person-environment fit', Journal of Applied Psychology, Vol. 91, No. 4, pp.802-827.

Engeström, Y. (2000) 'Activity theory as a framework for analyzing and redesigning work', Ergonomics, Vol. 43, No. 7, pp.960-974.

Engeström, Y., Miettinen, R., Theory, I.C.R.A., Punamäki, R.L., Brown, J.S., Heath, C. and Pea, R. (1999) Perspectives on Activity Theory, Perspectives on Activity Theory, Cambridge University Press [online] https://doi.org/10.1017/cbo9780511812774.

Fenker, M. (2008) Towards a Theoretical Framework for Usability of Buildings, Usability of Workplaces - Phase 2, CIB Report 316, CIB.

Forlizzi, J. (2008) 'The product ecology: understanding social product use and supporting design culture', International Journal of Design, Vol. 2, No. 1, pp.11-20.

Gerdenitsch, C., Korunka, C. and Hertel, G. (2018) 'Need-supply fit in an activity-based flexible office: a longitudinal study during relocation', Environment and Behavior, Vol. 50, No. 3, pp.273-297.

Greene, C. and Myerson, J. (2011) 'Space for thought: designing for knowledge workers', Facilities, Vol. 29, No. 1, pp.19-30.

Haapakangas, A., Hongisto, V., Eerola, M. and Kuusisto, T. (2017) 'Distraction distance and perceived disturbance by noise - an analysis of 21 open-plan offices', J. Acoust. Soc. Am., Vol. 141, No. 1, p.127.

Haapakangas, A., Hongisto, V., Varjo, J. and Lahtinen, M. (2018) 'Benefits of quiet workspaces in open-plan offices - evidence from two office relocations', Journal of Environmental Psychology, 16 March, Vol. 56, pp.63-75.

Haldi, F. and Robinson, D. (2011) 'The impact of occupants' behaviour on building energy demand', Journal of Building Performance Simulation, Vol. 4, No. 4, pp.323-338.

Hansen, G.K., Blakstad, S.H. and Knudsen, W. (2011) 'USEtool - evaluating usability', Hansen, G., Blakstad, S.H. and Knudsen, W. (Eds.): Methods Handbook, NTNU [online] https://www.ntnu.no/documents/20658136/21235909/USEtool_english.pdf/e891d71b-00ad4dc0-a985-1766696b17b1 (accessed 28 February 2020). 
Hirst, A. (2011) 'Settlers, vagrants and mutual indifference: unintended consequences of hot-desking', Journal of Organizational Change Management, Vol. 24, No. 6, pp.767-788.

Hongisto, V., Haapakangas, A., Varjo, J., Helenius, R. and Koskela, H. (2016) 'Refurbishment of an open-plan office - environmental and job satisfaction', Journal of Environmental Psychology, 6 January 2016, Vol. 45, pp.176-191, Elsevier Ltd.

Kaptelinin, V. and Nardi, B. (2007) Acting with Technology: Activity Theory and Interaction Design, Vol. 12, Edited by CambridgeFirst Monday, MIT Press, Massachusetts [online] https://doi.org/10.5210/fm.v12i4.1772.

Karlsson, M. (1996) 'A framework for the study of the relation between user and artefact', Engineering Psychology and Cognitive Ergonomics, Job Desi., Vol. 4, pp.379-386.

Kim, J. and De Dear, R. (2013) 'Workspace satisfaction: the privacy-communication trade-off inopen-plan offices', Journal of Environmental Psychology, Vol. 3 [online] https://doi.org/10. 1016/j.jenvp.2013.06.007.

Lahtinen, M., Ruohomäki, V., Haapakangas, A. and Reijula, K. (2015) 'Developmental needs of workplace design practices', Intelligent Buildings International, Vol. 7, No. 4, pp.198-214.

Lamb, S. and Kwok, K.C.S. (2016) 'A longitudinal investigation of work environment stressors on the performance and wellbeing of office workers', Applied Ergonomics, 25 July 2015, Vol. 52, pp.104-111.

Landivar, L.C. (2013) Disparities in STEM Employment by Sex, Race, and Hispanic Origin American Community Survey Reports, United States Census Bureau, No. September [online] https://selectra.co.uk/sites/default/files/pdf/stememployment.pdf (accessed 28 February 2020).

Lindahl, G., Hansen, G.K. and Alexander, K. (2012) 'The usability of facilities : experiences and effects', in Alexander, K. and Price, I. (Eds.): Managing Organization Ecologies, Space, Management and Organization, pp.105-116, Routledge.

Mateo-Cecilia, C., Navarro-Escudero, M., Escrig-Melia, T. and Estreder, Y. (2018) 'Creating office spaces in the Mediterranean. The importance of well-being, health and performance of office users', Informes de La Construcción, Vol. 70 No. 549 [online] https://doi.org/10.3989/id. 55050 .

Miles, M.B. and Huberman, A.M. (1994) An Expanded Sourcebook Qualitative Data, 2nd ed., SAGE Publications, London.

Morrison, R.L. and Macky, K.A. (2017) 'The demands and resources arising from shared office spaces', Applied Ergonomics, 22 November 2016, Vol. 60, pp.103-115, Elsevier Ltd.

Nijp, H.H., Beckers, D.G.J., Van De Voorde, K., Geurts, S.A.E. and Kompier, M.A.J. (2016) 'Effects of new ways of working on work hours and work location, health and job-related outcomes', Chronobiology International, Vol. 33, No. 6, pp.604-618, Taylor \& Francis.

Ostroff, C. and Judge, T.A. (2007) Perspectives on Organisational Fit, 1st ed., Psychology Press, New York [online] https://doi.org/https://doi.org/10.4324/9780203810026.

Rolfö, L., Eklund, J. and Jahncke, H. (2018) 'Perceptions of performance and satisfaction after relocation to an activity-based office', Ergonomics, Vol. 61, No. 5, pp.644-657.

Seddigh, A., Berntson, E., Jönsson, F., Danielsson, C.B. and Westerlund, H. (2015) 'Effect of variation in noise absorption in open-plan office: a field study with a cross-over design', Journal of Environmental Psychology, 16 September, Vol. 44, pp.34-44.

Soriano, A., Kozusznik, M.W., Peiró, J.M. and Mateo, C. (2018) 'The role of employees' work patterns and office type fit (and misfit) in the relationships between employee well-being and performance', Environment and Behavior, SAGE Publications Ltd. [online] https://oi.org/ $10.1177 / 0013916518794260$.

Van Koetsveld, R. and Kamperman, L. (2011) 'How flexible workplace strategies can be made successful at the operational level', Corporate Real Estate Journal, Vol. 1, No. 4, pp.303-319. 
Van Meel, J.J. (2000) The European Office; Office Design and National Context, 010 Publishers, Rotterdam [online] http://repository.tudelft.nl/view/ir/uuid:8718d3a3-f679-4b4a-9e1a40165c59ca4c/ (accessed 28 February 2020).

Vink, P., Koningsveld, E.A.P. and Molenbroek, J.F. (2006) 'Positive outcomes of participatory ergonomics in terms of greater comfort and higher productivity', Applied Ergonomics, Vol. 37, No. 4, pp.537-546.

Vischer, J.C. (2008) 'Towards an environmental psychology of workspace: how people are affected by environments for work', Architectural Science Review, Vol. 51, No. 2, pp.97-108.

Von Behren, S., Puhe, M. and Chlond, B. (2018) 'Office relocation and changes in travel behavior: capturing the effects including the adaptation phase', Transportation Research Procedia, Vol. 32, pp.573-584, Elsevier BV.

Windlinger, L. (2013) 'Summary for policymakers', Climate Change 2013 - The Physical Science Basis, pp.1-30.

Windlinger, L., Jansen, M., Feige, A. and Wallbaum, H. (2012) 'The role of office users in the sustainability of office buildings - an empirical investigation and implications for FM', Paper presented at 7th International Conference on Improving Energy Efficiency in Commercial Buildings, Frankfurt a. M., April, No. January, pp.1-10.

Windlinger, L., Nenonen, S. and Airo, K. (2015) 'Specification and empirical exploration of a usability concept in the workplace', Vol. 34, Nos. 11-12, pp.649-661. 


\section{Appendix}

Table 4 Interview guide

\section{General information}

Gender and age

Desk location (mark on the floorplan)

Position and nature of work

Seniority in the position and company

1 st order questions (always asked)

- 2nd order questions (asked if the interviewee needs further references or to provoke more elaborated answers)

a 3 rd order question of third order (asked if 2 nd order questions do not provide enough information)

\begin{tabular}{lc}
\hline Block of questions & Themes \\
\hline Questions & \\
\hline Office use and activities: &
\end{tabular}

Have you noticed if there are spaces or workstations more popular than others at the office?

Occupancy

- Do you feel any lack of available spaces or workstations?

Have you noticed if there are spaces or workstations less popular than others at the office?

- Do you think there are under-utilised spaces or workstations?

If you have to book any of them, how do you do it?

(Provide office floorplan including sections for 'home', 'own desk' and

Own work 'somewhere else', pen, markers and sticky notes to the participants)

What activities do you usually carry out while working on your own?

Describe briefly your routines.

- Where? When? Why? How often?

- What do you do when your work demands high concentration? Where do you concentrate? Why?

a Do you change place or take other actions in this regard?

- Where do you find inspiration for your work? Why?

- How do you handle tasks that demands less concentration, i.e., check e-mails, paperwork?

- How do you proceed if eventually you need to ask/tell something to someone?

- How do people approach you if they need to ask/tell you something?

- What if these conversations happen on the phone instead?

a Do you change place? Why?

b Are they long? Short? How often? Why that many calls? 
Table 4 Interview guide (continued)

\begin{tabular}{l}
\hline Block of questions \\
\hline Questions \\
\hline Office use and activities: \\
\hline How are your breaks along the day? Describe. \\
- What do you like to do during breaks? \\
- Coffee? Lunch? Quick-recovery between tasks? A moment of \\
relaxation? \\
- Where? Why that place? When? With whom? How many people? \\
How do you socialise with your colleagues at the office? \\
- Where? Why that place? When? With whom? How many people? \\
- Do you chat with the colleagues in your surroundings while you are \\
working at your desk? If yes, what kind of tasks do you do while \\
chatting?
\end{tabular}

Are there any social routines during the day? During the week? During the month?

- E.g., team meetings, 'fika', lunch, visits, leisure activities, etc.

- Do you enjoy them? Why?

What type of meetings do you have at the office?

- Informal meetings?

Work interaction/ group work

- Formal meetings?

- Meetings with customers/externals (equivalent)?

- Meetings over Skype/telephone?

- Where? Why that place? When? With whom? How many people?

- What activities do you perform together? (Exchange of info, group work, creativity sessions, etc.)

In general, how much of your working time is spent away from the office?

- Business trips, meetings, lectures, labs, home working, etc.

Is there any rule or agreement between colleagues on how to use the different office zones depending on your activity? What are those?

Social interaction

Themes

Are those rules respected?

In general, which are your favourite places at the office? Why?

Time away from the office

Rules and agreements

Workspace support:

(Provide the chart and the following labels to the interviewee one by one: visual privacy, auditory privacy, furniture ergonomics and functionality, office flexibility to host different activities, personal storage, availability of Favourite places shared spaces/ workstations, office layout, overall aesthetic design, greenery/nature references, internet/ phone coverage, printing facilities, office supplies, accessibility, IT hardware (PC, phone, screens, teleconference devices, projector, etc.), IT software (mail, operative systems, teleconference software, specialised software, etc.), access to views, air quality, daylight, climate, artificial lighting, acoustics, noise, social atmosphere, stress levels, parking/commuting possibilities, type of work you do, possibility to personalise the look of your workplace, possibility to work concentrated, collaboration with colleagues, meeting facilities, facilities for a break, job conditions) 
Table 4 Interview guide (continued)

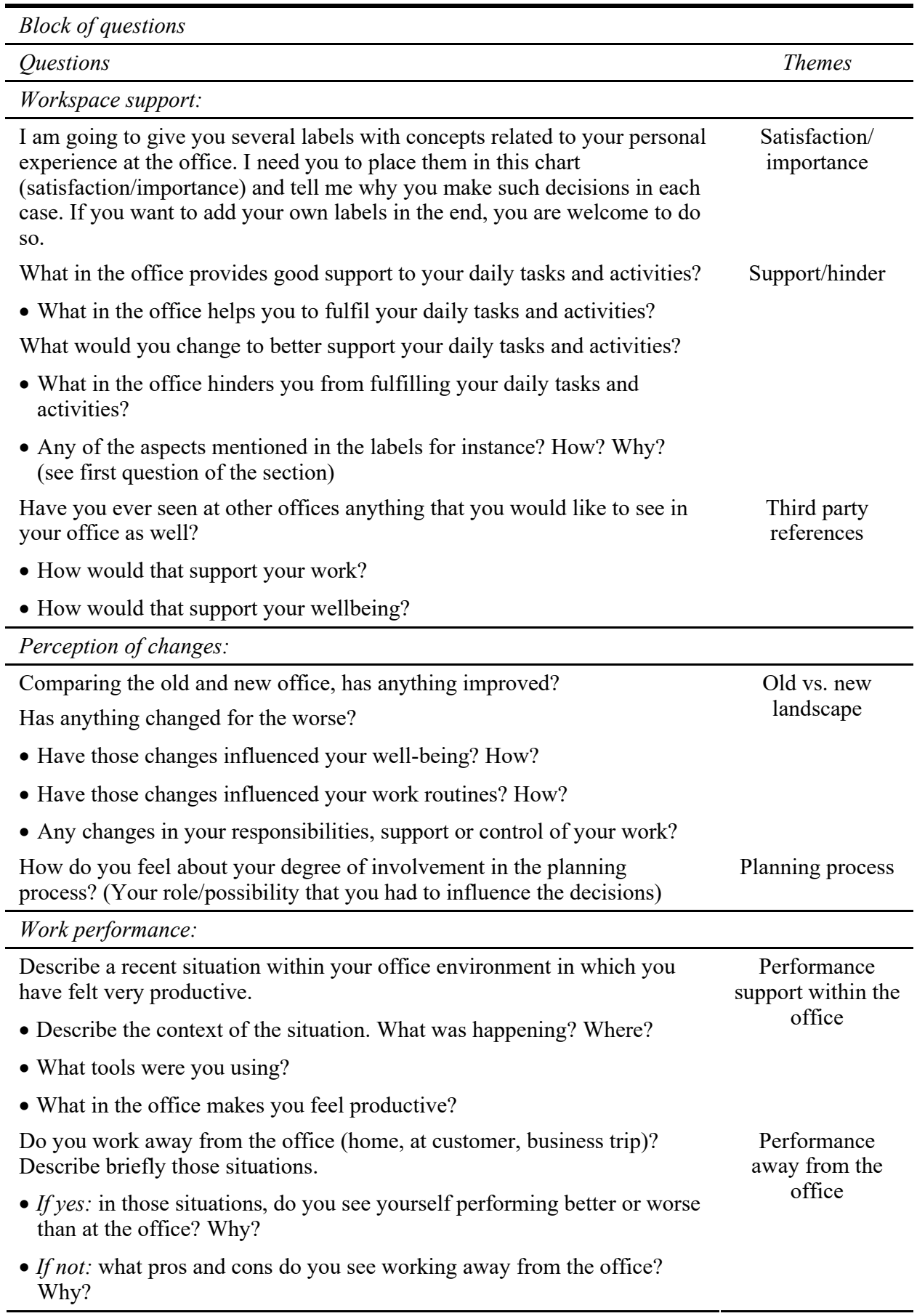


Table 4 Interview guide (continued)

\begin{tabular}{ll}
\hline Block of questions & \\
\hline Questions & Themes \\
\hline Perception of current work experience: & Overall \\
\hline Finally, having in mind all the aspects that matter to you, professionally & \\
and personally, what is the best of your job situation? & \\
What would you improve? & \\
- On a scale from 1-10, where 10 is the best possible job situation, what & \\
would bring you one step closer to 10 ? & \\
a And regarding the office space? & Closure \\
b What would be the first tiny signs of progress? & \\
Any further comment about your experience at the office?
\end{tabular}

